\title{
Aerogel Processing
}

\section{Thierry Woignier, Jean Phalippou, Florence Despetis, and Sylvie Calas-Etienne}

\section{Contents}

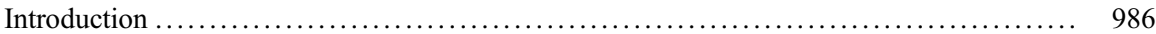

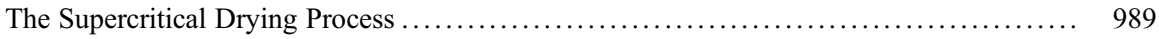

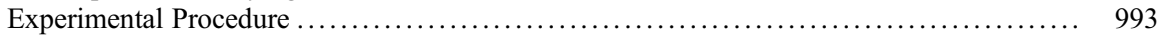

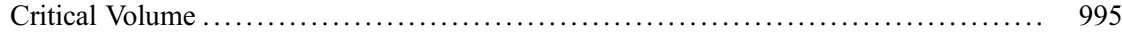

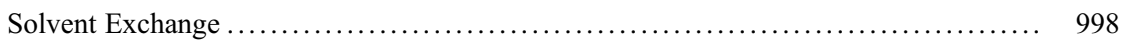

Stresses During the Supercritical Drying ..................................... 999

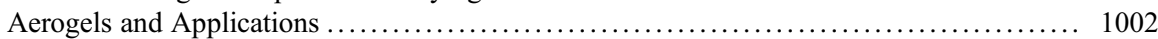

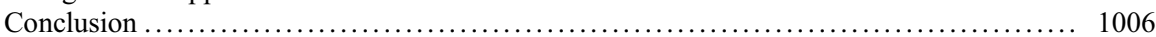

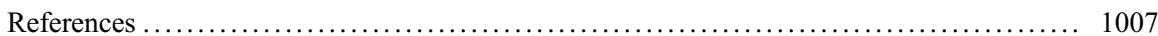

\begin{abstract}
One of the problems largely commented in the sol-gel science is how to make large bodies, because gels tend to crack during drying. The drying stresses are attributed to capillary phenomena and differential strain which result from a pressure gradient in the pore liquid. By the supercritical drying (SCD), the capillary stresses are eliminated and monolithic aerogel can be obtained. This chapter focuses on silica aerogel, the most studied aerogel. It presents an overview of the supercritical drying techniques, but also some of the remarkable
\end{abstract}

\footnotetext{
T. Woignier $(\bowtie)$

IMBE, CNRS, IRD, Aix Marseille Université, Avignon Université, Marseille, France

IRD - Campus Agro Environnemental Caraïbes, Le Lamentin, Martinique, France e-mail: thierry.woignier@univ-montp2.fr

J. Phalippou $\cdot$ F. Despetis $\cdot$ S. Calas-Etienne

Laboratoire Charles Coulomb, Université Montpellier 2, Montpellier Cedex 5, France e-mail: jean.phalippou698@orange.fr; Florence.Despetis@univ-montp2.fr; sylvie.etienne@umontpellier.fr
} 
aerogel properties (optical, mechanical, thermal and acoustical, etc.) with respect to its peculiar microstructure.

The chapter briefly presents other kinds of aerogels (oxides and chalcogenide aerogels, composite aerogels, organic aerogels, etc.) and a panel of potential applications.

\section{Introduction}

Aerogels are highly porous materials prepared by sol-gel process and supercritical drying. Silica aerogels exhibit remarkable properties (low density, high specific surface area, low refractive index and dielectric constant, low thermal conductivity and sound velocity, fractal structure, etc.). Aerogels are characterized by its three physical components: the solid phase, the pore phase (which can be as high as $99 \%$ ), and the large specific surface area (up to $1000 \mathrm{~m}^{2} \mathrm{~g}^{-1}$ ) separating the two phases. The characteristics and respective influence of the different components, chemical composition of the solid phase, kind of porosity (micro- and mesoporosity), and nature and accessibility of the interface will give some peculiar and unique properties to aerogels and lead to exotic applications (Aegerter et al. 2011; Woignier et al. 2007).

A silica gel results from a condensation of molecules or particles in a solvent. The Si precursor most used are alkoxides $\left(\mathrm{Si}(\mathrm{OR})_{4}\right)$ in which $\mathrm{OR}$ designates alkoxide groups. $\mathrm{R}$ is generally $\mathrm{CH}_{3}$ or $\mathrm{C}_{2} \mathrm{H}_{5}$. These monomers hydrolyze to form silanol groups which undergo condensation and form siloxane bridging bonds. The particles aggregate forming cluster and leading to the wet gels (Brinker 1990). It is constituted by tenuous and entangled chains of solid wetted by a liquid which occupies the whole volume located between solid chains. However, the different parameters, alkoxide concentration, alkoxide/water ratio, and catalyst nature, rule the aggregation process and the microstructure of the solid phase (pore volume and pore size, fractal structure, etc.). The liquid is a mixture of solvent, unreacted molecules, and by-products of chemical reactions.

It is obvious that only the network is of interest for material applications. There are many ways to remove the liquid located within the pores of the gel. Drying is often performed by a gentle solvent evaporation at temperatures close to room temperature. In the course of solvent evaporation, the shape of the liquid-vapor interface changes with time. The curvature radius of the meniscus decreases (Fig. 1), and, associated to this curvature, capillary forces take place. The pressure difference, $\Delta \mathrm{P}$, between vapor and liquid is given by Laplace's relation:

$$
\Delta P=-\frac{2 \gamma_{L V}}{R}
$$

where $\gamma_{L V}$ is the liquid-vapor surface energy and $\mathrm{R}$ is the curvature radius of the meniscus (here assumed spherical). The liquid is consequently under a tension stress, 
Fig. 1 Evolution of the curvature of liquid-vapor meniscus at the surface of a pore as a function of drying time, $\mathrm{t}$
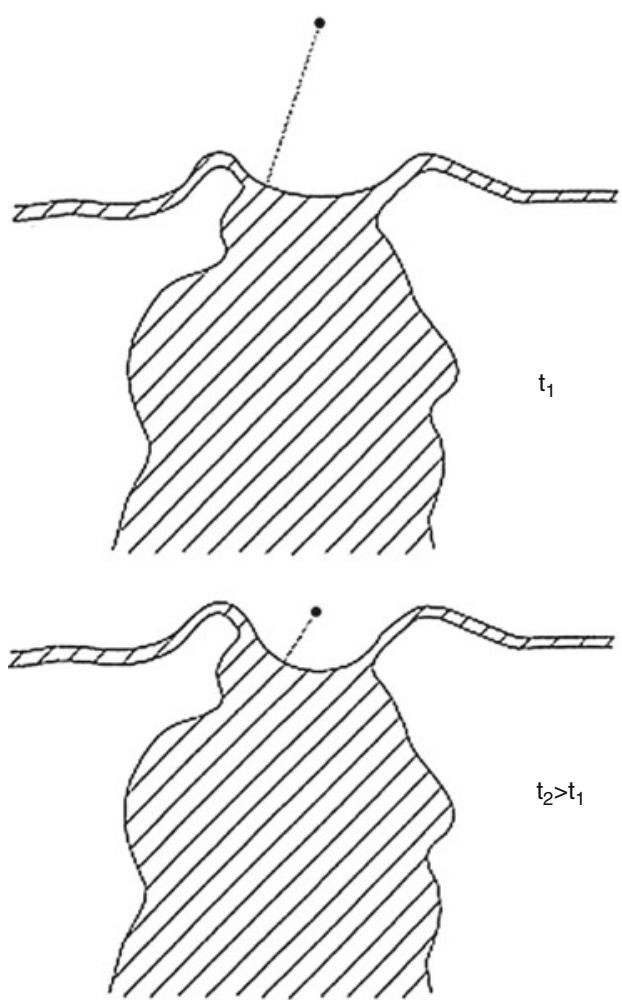

and the solid network is submitted to a compression stress. Because of the weak stiffness of the gel, network shrinkage occurs. The dried gel is named "xerogel" (from the Greek word $\chi \varepsilon \rho \rho \circ \zeta$ that means dried). The pore volume of the xerogel is well lower than that of the starting gel $(\sim 50 \%)$.

Hence pronounced textural modifications happen. This is the first serious drawback that we must avoid to preserve the expanded texture of the solid network.

The volume shrinkage of the gel during drying induces an increase of its stiffness. At a given time, the solid network is no more compliant, and the meniscus recedes in the pores. The capillary stress increases (since the curvature radius corresponds to that of the shrunk pore), and the liquid flows from the core of the gel to the surface. This flow is hindered by the tortuosity of solid phase of the gel. A gel is poorly permeable because the size of the pores is in the range $0.2-10 \mathrm{~nm}$ indicating that a gel is a mesoporous material. According to the Darcy's law, the liquid flow, $J$, is related to permeability, $D$, by the relation:

$$
J=-\frac{D}{\eta} \nabla P
$$

where $\nabla P$ is the pressure gradient and $\eta$ is the liquid viscosity. 
Because of the stress gradient, the solid network may crack and the cracking is related to the evaporation rate. Indeed the evaporation rate controls the liquid flow. The drying of the gel has been precisely studied by G.W. Scherer (Brinker 1990). A gel slowly dried will produce a free crack xerogel. Many authors report drying treatments, the duration of which is of several months.

Cracking of the solid part of the gel is the second drawback encountered during drying. Since the main consequences of drying are the shrinkage and the breakage, several approaches have been proposed to overcome these drawbacks. We will describe the ambient pressure drying, freeze drying, and supercritical drying which have been investigated to circumvent these difficulties.

Ambient pressure drying techniques were proposed to synthesize monolithic dried gels sometimes called "aerogel-like materials," thanks to the low bulk density obtained. These methods propose to control the drying step by: (1) the increase of the gel mechanical properties and permeability or (2) the decrease of the capillary stresses gradient by the lowering of the surface energy or the narrowing of the pore size distribution.

The increase of the stiffness of the solid part of the gel by a dissolution-redeposition effect allows to preserve the monolithicity of the gel while reducing the shrinkage (Mizuno et al. 1988), and aging the wet gel in a solution containing monomers gives analogous results (Einarsrud 1998). The nanocomposite approach (Toki et al. 1988; Reynes et al. 2001; Aravind et al. 2007; Anez et al. 2014) proposes the addition of silica soot particles to increase the mechanical properties and permeability of the wet gels allowing the porous structure to resist to the drying stresses. Another way to increase the mechanical strength of silica aerogels consists of filling the pores of the gel with a solution of diisocyanate. A deposition and a growth of polyhexamethylene diisocyanate occur and cause an increase of the neck between silica particles. This composite aerogel is less hydrophilic than silica. In addition the denser samples exhibit a non-fragile behavior, and their mechanical strength is 100 times higher than that corresponding to pure silica aerogel (Leventis et al. 2000). Cracking has been chemically avoided by adding to the starting solution some compounds (drying control chemical additives, DCCA) which give rise to gel having a narrow pore size distribution and controlling the drying step (formamide, glycerol, oxalic acid, PEG ) (Shoup 1988; Hench 1986; Martin et al. 2001; Venkateswara Rao and Kulkami 2003). To minimize the capillary forces, hydrophobic surface (Land et al. 2001) prevents the shrinkage, and after the solvent is removed, the volume comes back to the initial wet gel volume (Mezza et al. 1999). Prakash et al. (Prakash et al. 1995) change the surface of the wet silica gels using hexane to promote reversible shrinkage (springback effect).

Freeze drying consists of lowering the temperature to induce the liquid solidification (crystallization). The solvent is then removed from its vapor state by decreasing the pressure (sublimation) (Pajonk 1989). This process applies well to solvents showing an appreciable vapor pressure at temperatures lower than crystallization temperature. Low molecular weight alcohols have a low crystallization temperatures (methanol, $-94^{\circ} \mathrm{C}$; ethanol, $-117^{\circ} \mathrm{C}$ ), and water which transforms into ice shows a volume change associated to this transformation. The solid part of the gel is stressed 
and usually breaks into small pieces (Scherer 1993). Moreover the sublimation rate is quite slow. It is of about $140 \mathrm{~kg} / \mathrm{m}^{2} . \mathrm{h}$ at $15^{\circ} \mathrm{C}$. A solution, which may avoid the volume change produced by crystallization, is to transform liquid into glass. Unfortunately glass formation domain often occurs near eutectic point composition. As exemplified the glass temperature of mixture $\mathrm{H}_{2} \mathrm{O}-\mathrm{CH}_{3} \mathrm{OH}$ is too low $\left(-157^{\circ} \mathrm{C}\right)$ (Vuillard and Sanchez 1961) to perform the sublimation at appreciable rate. Finally, one among the best liquids seems to be terbutanol whose melting temperature is $25^{\circ} \mathrm{C}$ and which has a sublimation rate of $2800 \mathrm{~kg} / \mathrm{m}^{2}$.h at $0{ }^{\circ} \mathrm{C}$. This solvent is not usual and a previous solvent exchange is often required. The textural properties of the gel such as the pore volume and the pore size distribution are approximately preserved. Nevertheless it seems difficult to obtain monolithic samples having significant thickness (higher than $10 \mathrm{~mm}$ ) (Degn and Engell 1989). A detailed analysis of the nucleation and crystallization phenomena occurring in the liquid wetting the solid part of the gel has been done by Scherer (1993). Crystallization starts from the liquid located at the external gel surface, and the crystal-liquid interface moves from the surface to the core. Thus stresses appear as a consequence of the solid crust which forms at the surface and the volume change associated to the liquid-crystal transformation.

The main advantage of the ambient pressure method is that they do not require dangerous high-pressure equipment; however several steps of solvent exchange and chemical reaction are necessary. Moreover the initial wet gel porous structure is affected during the drying step. The freeze drying is not appropriate to obtain monolithic dried gels.

We will now present the super critical drying method which is generally rapid and allows preserving the tailored chemical composition and microstructure of the wet gels.

\section{The Supercritical Drying Process}

The supercritical drying process has been proposed by Kistler (1932) to dry, without textural modification, very tenuous solids wetted with a solvent.

The main idea is to avoid capillary forces, which occur during drying, by a peculiar pressure and temperature schedule applied to the liquid. Regarding the liquid phase of the gel, it is obvious that one can modify its state by changing thermodynamic parameters such as the pressure and the temperature.

Figure 2 shows a typical phase diagram for a pure compound. The parameters, $P$, $\mathrm{T}$, and $\mathrm{v}$ (usually the specific volume), are the variables which determine the state equation.

Figures 3 and 4 correspond to some projections of the previous three-dimensional diagram. The principle of supercritical drying is easily understood from Fig. 4. The point a defines the couple pressure-temperature at which the three states of the compound are in equilibrium. Under atmospheric pressure, $\mathrm{P}_{\mathrm{at}}$, the liquid transforms into vapor at boiling temperature $\left(\mathrm{T}_{\mathrm{b}}\right)$. The point $\mathrm{c}$ is the boundary of the vaporization curve corresponding to liquid-vapor separation. The point $\mathrm{c}$ is named the critical 
Fig. 2 Typical $\mathrm{P}, \mathrm{T}$, and $v$ diagram of a chemical compound

Fig. 3 Pressure-specific volume diagram issued from the diagram in Fig. 2
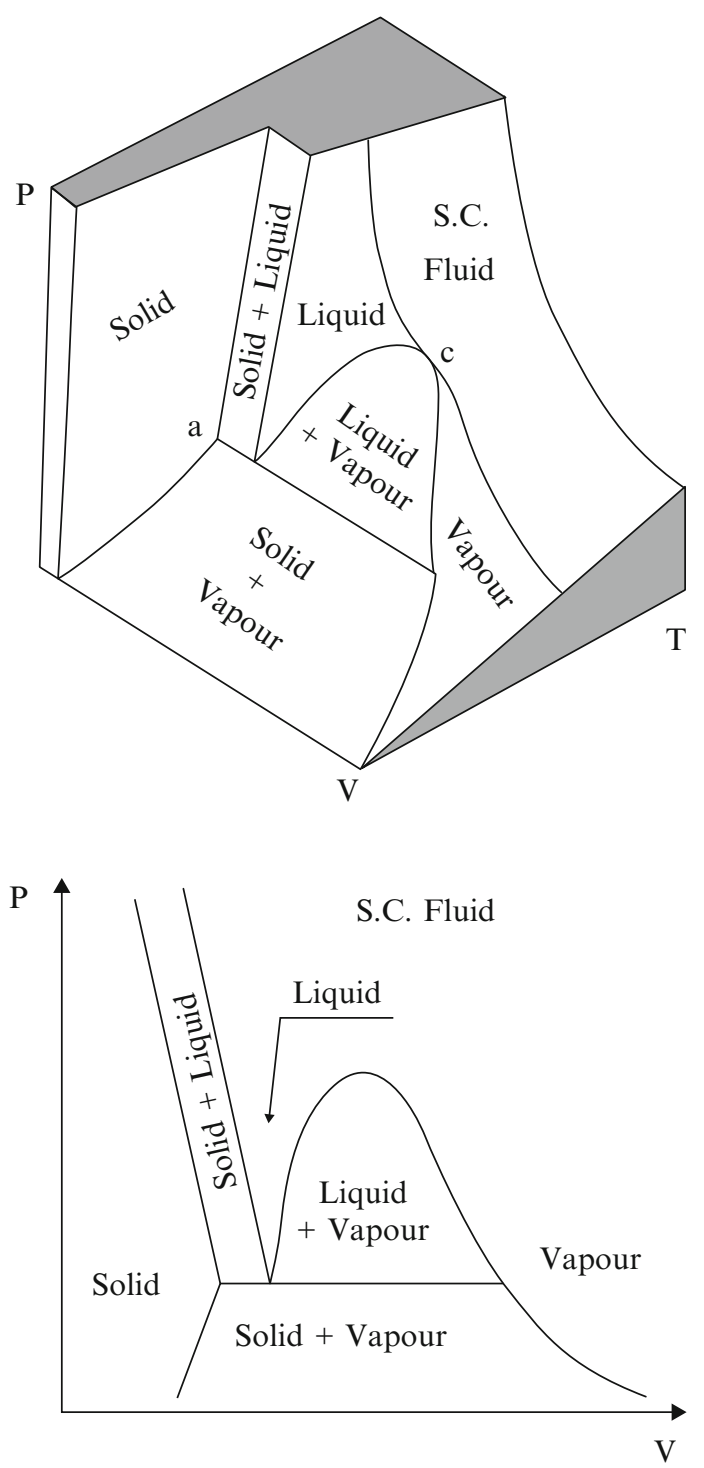

point. For a given compound, the critical point is determined by associated critical pressure and temperature values. Above this point there is a continuum between the liquid and the vapor which can no more be distinguished. In this domain, there is a unique state named supercritical fluid (SF). This domain is not well defined. However a crude approximate consists in locating the supercritical fluid domain by a $\mathrm{P}$ and $\mathrm{T}$ area as indicated in Fig. 4.

At room temperature $\left(\mathrm{T}_{\mathrm{R}}\right)$ starting with a liquid $(\mathrm{N})$ and increasing both the temperature and the pressure, the compound follows the path $\mathrm{N} \rightarrow \mathrm{Q}$ (Fig. 5). 
Fig. 4 Pressure-temperature diagram showing the different domains solid, liquid, and vapor and supercritical fluid (SF)
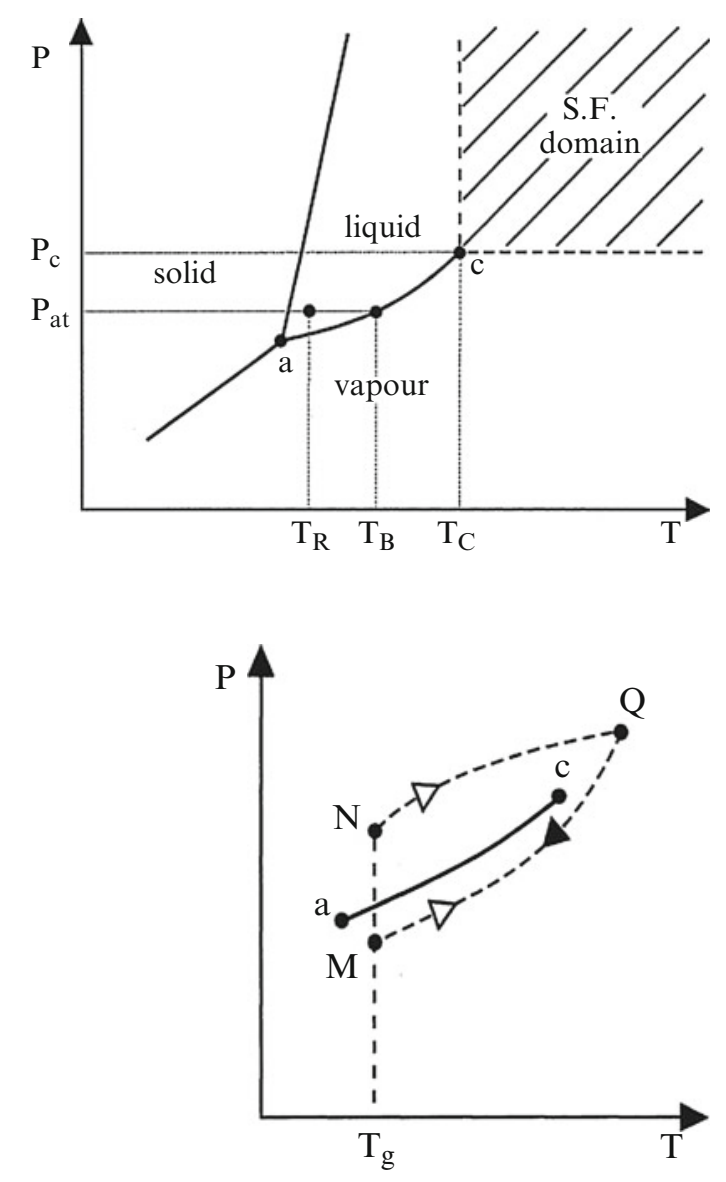

Fig. 5 Different paths to reach the supercritical fluid domain

At $\mathrm{Q}$, the compound is a supercritical fluid. Starting with the vapor state at low pressure (M) and increasing the temperature and the pressure, the compound reaches the point Q where it is in the same state than that previously mentioned. We thus obtained the same homogeneous and unique state using different paths.

From the supercritical fluid state (point Q), an adequate decrease in the temperature and pressure (see full arrow) will lead to the vapor state (point M). The net effect of these successive steps results in the transformation of liquid into vapor. A drying step has been carried out. The change from the liquid to the vapor follows a path that avoids the vaporization curve (ac). During heating, the surface energy associated to the interface liquid-gas progressively decreases and vanishes when the superfluid state is attained. Consequently capillary forces (see Eq. (1) are no more acting, and the solid part of the gel does not suffer stresses. Drying does not induce stresses, and the texture of the solid network does not collapse. The aerogel, in principle (see section "Stresses During the Supercritical Drying"), does not exhibit shrinkage; its porous volume is quite identical to that of the starting gel. In addition, 
Table 1 Critical parameters of compounds used to perform SCD

\begin{tabular}{l|l|l}
\hline & $\boldsymbol{P}_{\mathbf{C}}(\mathbf{M P a})$ & $\boldsymbol{T}_{\mathbf{C}}\left({ }^{\circ} \mathbf{C}\right)$ \\
\hline Ether & 3.6 & 192.5 \\
\hline Acetone & 4.6 & 235 \\
\hline 1-Butanol & 4.3 & 290 \\
\hline 1-Propanol & 5.1 & 265 \\
\hline Ethanol & 6.3 & 240 \\
\hline Methanol & 7.9 & 240 \\
\hline $\mathrm{N}_{2} \mathrm{O}$ & 7.2 & 36.5 \\
\hline $\mathrm{CO}_{2}$ & 7.3 & 31.1 \\
\hline $\mathrm{H}_{2} \mathrm{O}$ & 22 & 375 \\
\hline
\end{tabular}

this drying process must lead to crack-free material when performed under controlled conditions. Table 1 Reference source not found. summarizes the different solvents used to perform supercritical drying. The critical pressure and temperature can achieved using an autoclave made of stainless steel.

Supercritical drying solvents belong to two families: organic and inorganic solvents. The organic solvents are mainly alcohols, ether, and acetone, but for safety conditions, ether and acetone are rarely used. Among the alcohols, those having short length are preferred because they do not decompose at high temperature and pressure. Moreover, because of their quite high critical temperature, organic solvents can react with the solid network (esterification reaction). In the case of silica gel prepared from hydrolysis of organometallic compounds diluted in alcohol, the nature of the surface of solid particle is modified according to the reaction: $\mathrm{Si}-\mathrm{OH}+\mathrm{R}-\mathrm{OH}$ $\rightarrow \mathrm{Si}-\mathrm{OR}+\mathrm{H}_{2} \mathrm{O}$.

The silanol $(\mathrm{Si}-\mathrm{OH})$ surface groups are replaced by chemical groups $\mathrm{Si}-\mathrm{OR}$ which exhibit a hydrophobic effect. A silica aerogel obtained by alcohol SCD floats when placed onto water. With time, air moisture will react with $\mathrm{Si}-\mathrm{OR}$. Consequently the aerogel becomes hydrophilic, and water absorbs on the pore surface inducing capillary forces. The monolithicity of the aerogel can be lost.

The second drawback of organic solvent used in supercritical drying process is associated to the nature of the solid network. Because of the required high critical temperature, only gels built up with strong chemical bonds are able to resist the heat treatment. Inorganic solvents which allow supercritical drying are fluorinated compounds (Freon), $\mathrm{SO}_{2}$, and carbon dioxide (Woignier 1984). Fluorinated compounds are not authorized because they cause serious damaging of the ozone layer. Water supercritical drying is always avoided because under supercritical conditions it behaves as a strong mineralizer toward inorganic material and more particularly with amorphous silica.

The most attractive solvent is the carbon dioxide. It is chemically unreactive and its critical temperature is close to room temperature. It permits to dry gels which do not suffer temperatures higher than $100{ }^{\circ} \mathrm{C}$ under suitable safety conditions. However the starting gels are synthesized at room temperature using alcohol and water as solvents. Consequently the first step of the drying procedure must include a solvent exchange with $\mathrm{CO}_{2}$ liquid or $\mathrm{CO}_{2}$ supercritical fluid. This exchange involves 
solvents miscible with $\mathrm{CO}_{2}$ (Francis 1954 and Baker and Anderson 1957]. It is worth noticing the success in forming directly gels in supercritical carbon dioxide [Loy et al. 1997]. This synthesis way seems attractive since avoiding initial hazardous organic solvent extraction.

A disadvantage of $\mathrm{CO}_{2}$ supercritical drying is related to the hydrophilic property of resulting aerogels. They absorb water with time, and capillary condensation occurs inducing capillary forces that in turn can lead to textural damage.

\section{Experimental Procedure}

Figure 6 shows a schematic autoclave setup. Sometimes the autoclave is equipped with sapphire windows permitting observation and optical measurements. $\mathrm{CO}_{2}$ supercritical drying equipment needs a pressure compressor and a chiller device to transform $\mathrm{CO}_{2}$ vapor into $\mathrm{CO}_{2}$ liquid.

Alcohol supercritical drying is performed directly with gel imbedded with alcohol. The usual thermal schedule (Fig. 7) consists in a heating step up to a temperature $\left(\mathrm{T}_{\mathrm{W}}\right)$ and a pressure $\left(\mathrm{P}_{\mathrm{W}}\right)$ higher than the critical point $\left(\mathrm{Tc}, \mathrm{P}_{\mathrm{c}}\right)$. At the point $\mathrm{Q}$ an
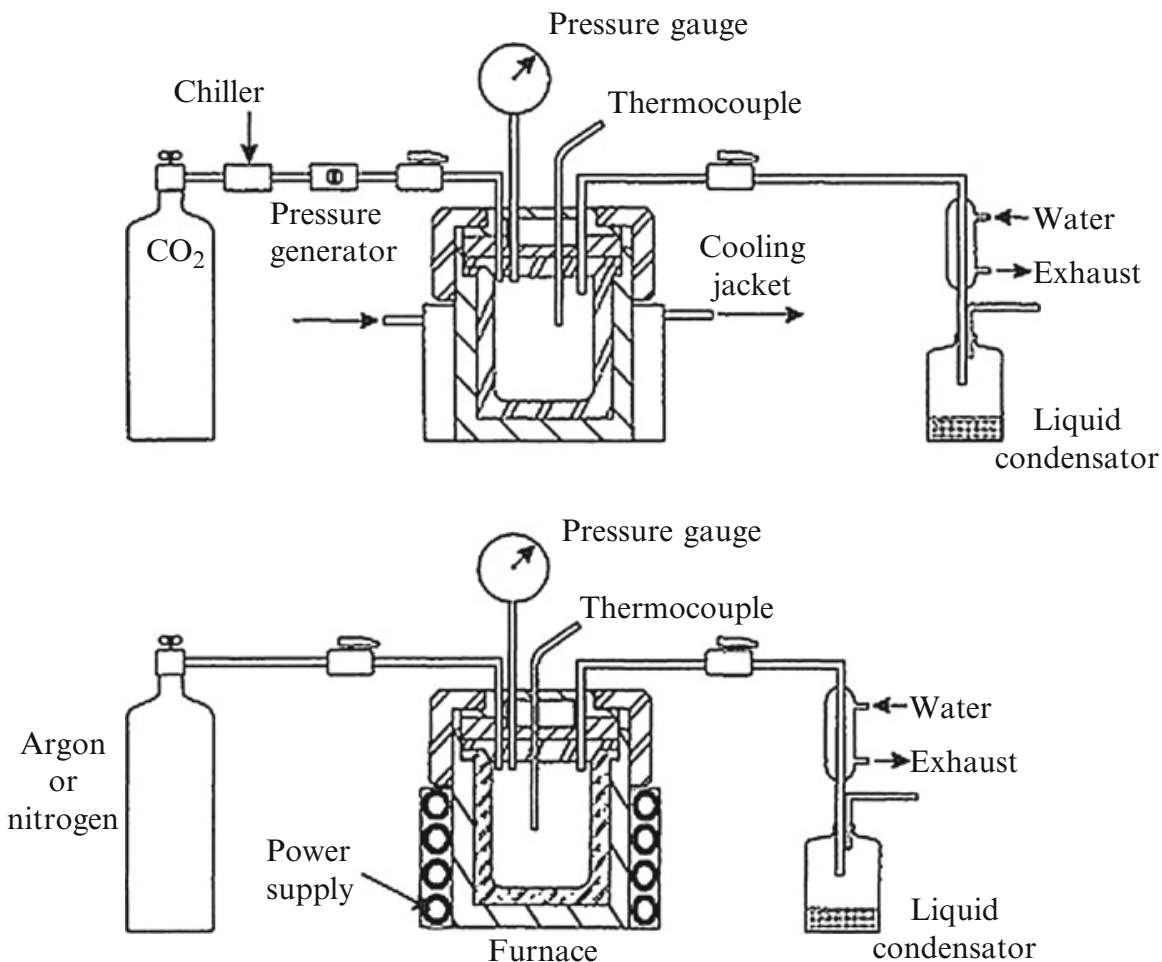

Fig. 6 A schematic apparatus with equipment allowing to perform supercritical drying 
Fig. 7 Usual $P$ and $T$ path allowing to obtain aerogel

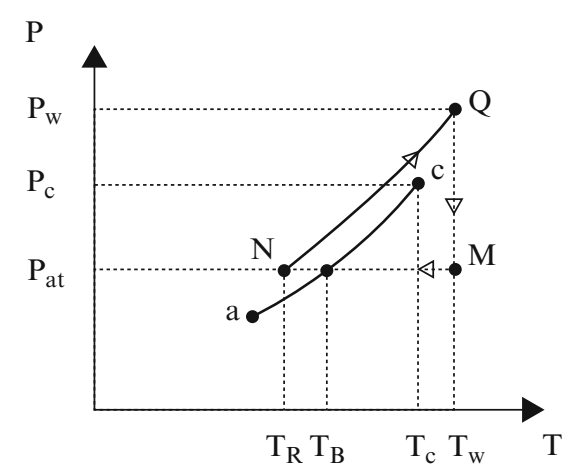

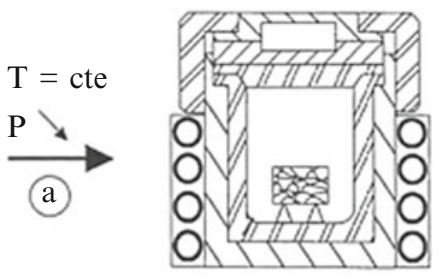

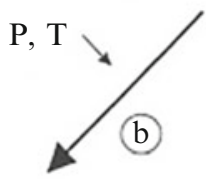

Liquid

Vapour

S. C. Fluid

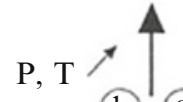

(b) (a)
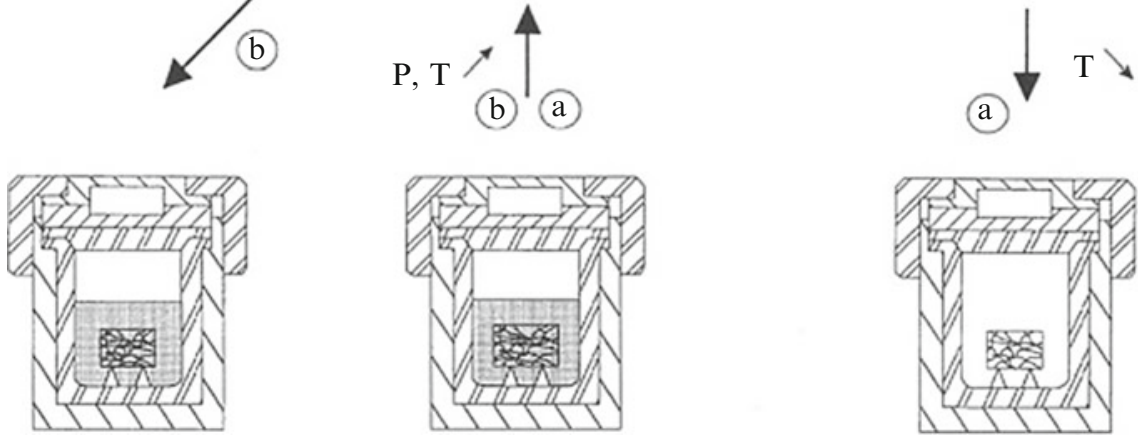

3

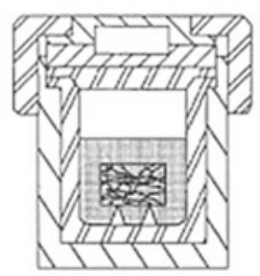

1

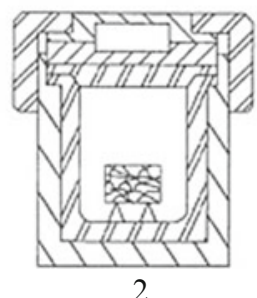

Fig. 8 Ways to compare the geometrical dimensions of samples as a function of the different steps leading to aerogels

isothermal treatment is performed, while the output valve is gently opened to vent the autoclave. When the pressure in autoclave approaches the atmospheric pressure (point $\mathrm{M}$ ), the autoclave is fluxed with a neutral gas (nitrogen or argon).

The autoclave is then cooled down to room temperature, $T_{R}$. The autoclave fluxing may be carried out during cooling at any temperature higher enough to avoid liquid condensation within the smallest pores of the gel. Since the solvent vapor is changed by an inert gas, no liquid condensation arises.

Figure 8 schematically displays the different steps corresponding to a classical supercritical schedule (path (a)). Thus the geometrical dimensions of the gel and 
Fig. 9 Pressurization of autoclave at the onset of supercritical drying

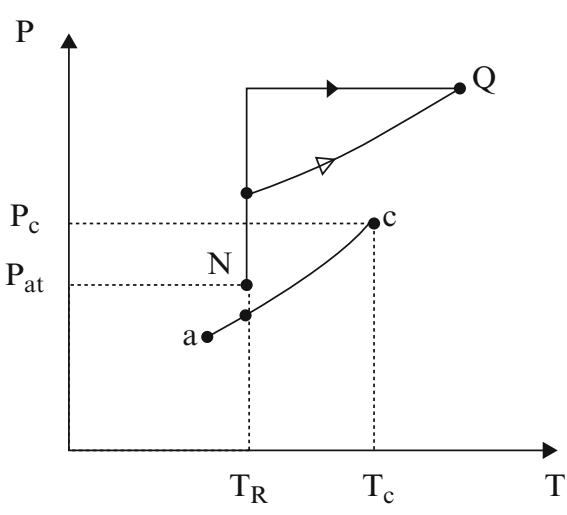

aerogel can be directly estimated by comparing the states 1 and 2 . The volume lost is easily calculated from the bulk density of aerogel. On the other hand, the path $b$ is sometimes employed to have information about the textural changes induced by chemical reactions occurring during the temperature and the pressure increases. This path consists in cooling down the autoclave after the initial heating step. In that case an isothermal treatment is not performed. The supercritical fluid separates into vapor and liquid as the temperature decreases. Using the thermoporometry technique which works on wetted samples, the difference in textural properties between the starting gel (state 1) and the gel which has been only submitted to the initial heating step (state 3) is evaluated (Pauthe et al. 1991).

Some authors (Woignier 1984; Mulder and Van Lierop 1986) suggest to pressurize the autoclave cell with a neutral gas and then to increase the temperature. The pressure increases with temperature or can be maintained constant by a gentle opening of a venting valve, while the temperature rises (Fig. 9). The escaping gas is always condensed (during heating and/or depressurization step) to be further analyzed.

With respect to low temperatures involved in the $\mathrm{CO}_{2} \mathrm{SCD}$, it is possible to increase the pressure using a piston located inside the autoclave vessel or by introducing directly $\mathrm{CO}_{2}$ pressured with an external compressor.

\section{Critical Volume}

In the case of organic solvent like alcohols, the autoclave is usually filled with an additional amount of solvent. This additional solvent is often poured on the top of the gel and between the walls of the autoclave and the container in which the gel has been formed (Fig. 10). The role played by the additional solvent may be understood thanks to the Fig. 11. The specific volume, v, is the ratio: volume of autoclave/mass of alcohol. When the autoclave contains a high amount of liquid, the specific volume is low. Conversely an autoclave mainly filled with vapor corresponds to a high v value. 
Fig. 10 Autoclave vessel containing an additional amount of solvent
Fig. 11 Liquid-vapor separation curve in the $\mathrm{T}$ and $\mathrm{v}$ diagram. Note that solid-liquid and solid-vapor domains are not shown for clarity
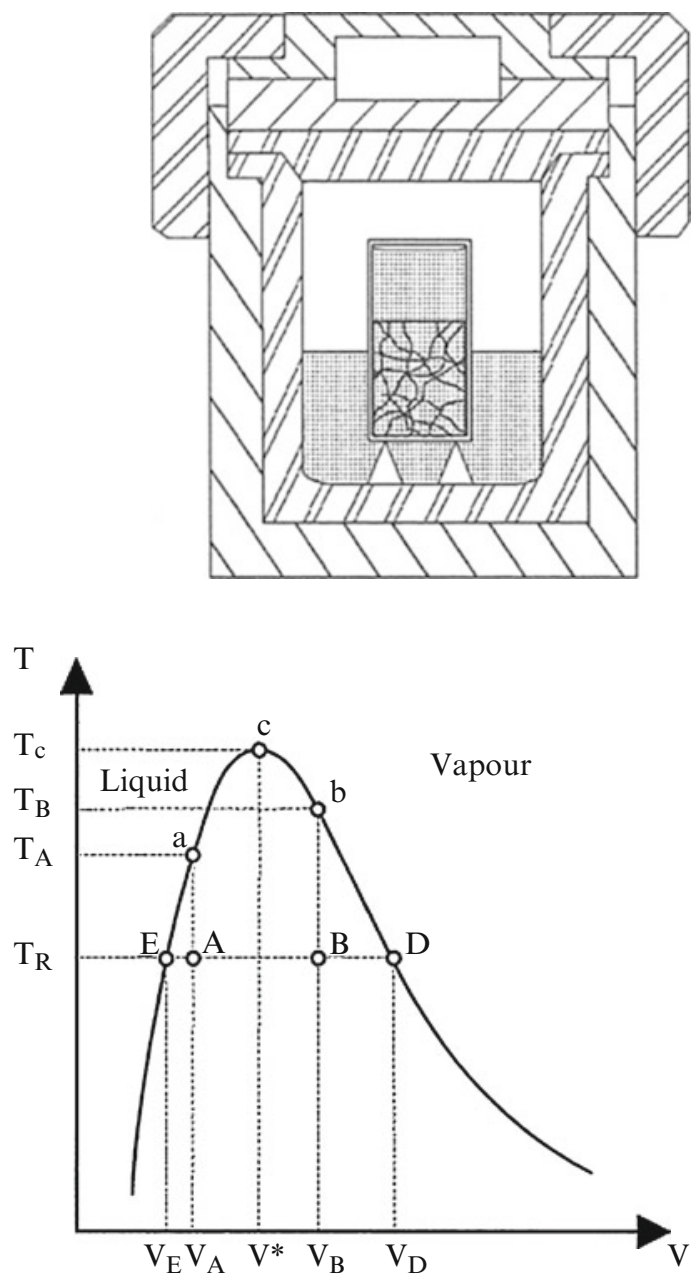

A and B points correspond to room temperature differently filled autoclave. Obviously the autoclave contains an amount of liquid and vapor which may be estimated from the points $\mathrm{E}$ and D. Starting with a mixture represented by A and increasing the temperature of autoclave, the respective quantities of liquid and vapor vary (line $A \rightarrow a$ ). When the temperature reaches $T_{a}$, the solvent is under a liquid state. This means that the interface of the liquid-vapor interface moves toward the top of the autoclave during heating.

Conversely a mixture of liquid and vapor corresponding to $\mathrm{v}_{\mathrm{B}}$ (point $\mathrm{B}$ ) will transform into gas at a temperature above $T_{b}$. Since the solvent is entirely converted into vapor, the interface recedes and disappears when the last drop of liquid located at the autoclave bottom evaporates. Figure 12 summarizes the different evolutions of the liquid-vapor interface when the temperature is ramped. For the specific volume, $\mathrm{v}^{*}$, the level of the interface liquid-solid remains about constant with temperature rise. 
Fig. 12 Evolution of liquid-vapor interface during a heating treatment as a function of specific volume values. The arrows indicate the interface displacement
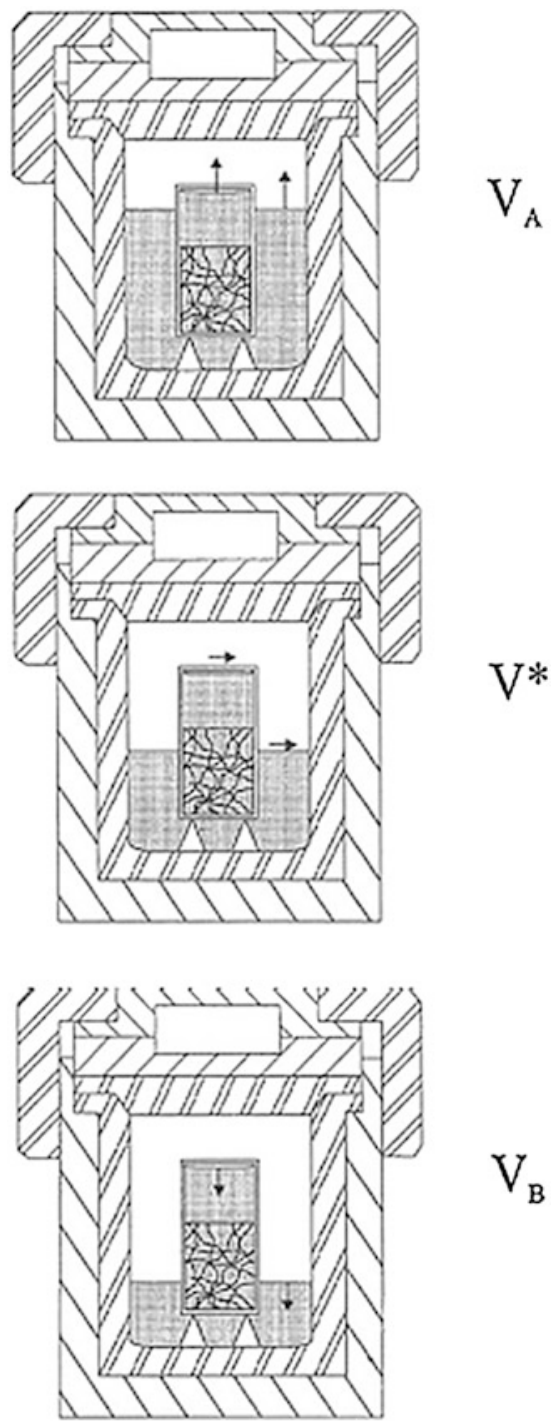

Thus addition of an amount of liquid solvent is advised to avoid the moving of interface downward. If additional solvent is too low ( $\operatorname{such}$ as $\mathrm{v}_{\mathrm{A}}$ ), at a moment during heating, the solid part of the gel is not wetted with liquid, and capillary forces are created. The upper part of the gel shows an extended shrinkage due to capillary stresses, while the bottom exhibits a small shrinkage. Such differential shrinkage between the upper and the lower part of aerogel indicates that the supercritical drying has been performed with an inadequate solvent amount. For silica gels prepared with alkoxysilane and alcohol as solvents, the critical specific volumes are methanol $3.67 \mathrm{~cm}^{3} \mathrm{~g}^{-1}$ and ethanol $3.62 \mathrm{~cm}^{3} \mathrm{~g}^{-1}$. 
It has been experimentally evidenced that the shrinkage and the monolithicity of aerogel depend on the amount of additional solvent (Phalippou et al. 1990). The effect of the initial prepressure corresponds to a decrease on the v scale in Fig. 11. A nitrogen (or argon) prepressure is roughly equivalent to a lower available volume in the autoclave. For a given amount of solvent, the specific volume is lowered, and the temperature increase causes the liquid level to climb. The prepressure permits to decrease the volume of solvent required to perform supercritical drying in conditions preserving the texture of the solid.

A few variants can be found in the literature. It has been observed that for silica gels obtained from alkoxide compounds, the gelation can be done during the temperature rise (Prassas et al. 1984). On the other hand, it is possible to faster the aerogel production owing to a fast pressure increase associated to liquid expansion in a mold. A fritted mold permits the internal fluid to escape slightly to maintain the pressure constant (Gross et al. 1998). In this process the rate of leakage is equal to that of alcohol expansion.

For $\mathrm{CO}_{2} \mathrm{SCD}$ the critical volume is not a parameter of interest since the organic solvent which must be replaced with $\mathrm{CO}_{2}$ liquid prior to supercritical drying.

\section{Solvent Exchange}

In the $\mathrm{CO}_{2}$ supercritical drying, the solvent exchange is the step which is the most time consuming. When the initial solvent is water, a first solvent exchange is required because liquid $\mathrm{CO}_{2}$ and water are not miscible. Amyl acetate, alcohol, and acetone which are miscible with $\mathrm{CO}_{2}$ liquid are generally used.

When the washed gel yet contains small quantities of water, the phase diagrams $\left(\mathrm{CO}_{2}-\mathrm{H}_{2} \mathrm{O}\right.$-ethanol) (Baker and Anderson 1957) and $\left(\mathrm{CO}_{2}-\mathrm{H}_{2} \mathrm{O}\right.$-acetone) (Panagiotopoulos and Reid 1985) permit to select parameters (P, T) corresponding to one phase region. A complete removing of water traces is required if one wants to avoid some difficulties occurring during depressurization. These difficulties originate from the selective extraction of organic compounds with $\mathrm{CO}_{2}$, while water is not eliminated. For silica gel, a water-free gelation has been produced from TMOS and formic acid within the supercritical fluid $\mathrm{CO}_{2}$. Since this organic solvent is miscible with $\mathrm{CO}_{2}$ (Loy et al. 1997), the solvent exchange which is the limiting step of $\mathrm{CO}_{2}$ is avoided and the supercritical drying directly performed.

The quality of the liquid replacement is crucial for obtaining monolithic aerogel sample. This crucial stage has been investigated by several authors, and it was evidenced that alcohol removing depends on its location. Free alcohol located outside the gel is rapidly extracted by $\mathrm{CO}_{2}$, while alcohol within the gel is difficult to remove. For cylindrical gel with a diameter, $\mathrm{d}$, of $15 \mathrm{~mm}, 3 \mathrm{~h}$ is needed to replace alcohol with $\mathrm{CO}_{2}$. This duration depends mainly on the details of the gel texture and varies as (Van Bommel and de Haan 1994):

$$
t \propto d^{2}
$$

where $d$ is the diameter of cylindrical samples. 
The diffusion of liquid $\mathrm{CO}_{2}$ into a gel filled with ethanol has been followed by the interface motion between the transparent and the damaged zone observed in the resulting aerogel. An aerogel completely exchanged is monolithic and transparent, while the part of the gel which contains residual alcohol is damaged (Rogacki and Wawrzyniak 1995). The time evolution of the alcohol concentration in liquid $\mathrm{CO}_{2}$ has been precisely measured using online chromatograph (Wawrzyniak et al. 2001). The solvent exchange with $\mathrm{CO}_{2}$ induces a dimensional change of gel sample. For example, the gel sample shrinks as acetone is replaced with $\mathrm{CO}_{2}$. The shrinkage is due to compressive stresses which act on the solid part as a result of osmotic pressure. This osmotic phenomenon arises from the increase of interface energy when solid acetone transforms into solid-liquid $\mathrm{CO}_{2}$ (Wang and $\mathrm{Wu} 1998$ ).

\section{Stresses During the Supercritical Drying}

When aerogels are obtained free of cracks that means during SCD process, the gel has suffered minor stresses. Experiments indicate that both thermodynamic parameters $(\mathrm{P}, \mathrm{T})$ and dimension and nature of the gel play a very important role on monolithicity.

Numerous investigations deal with silica gels. Silica gels belong to two families depending upon the $\mathrm{pH}$ preparation conditions. Silica gels obtained from acid hydrolysis of alkoxides have a mean pore size in the range of 3-4 nm. For basecatalyzed gels, the mean pore size is shifted toward higher values. The behavior of silica gels varies with respect to these different textural properties.

Associated to the pore size and the pore size distribution, the gels have different permeability values. According to the Carman-Kozeny equation, the permeability (K) of a gel is given by $\mathrm{K} \alpha(1-\rho) \mathrm{r}$, where $\rho$ is the bulk density and $\mathrm{r}$ is the mean pore radius; larger $\mathrm{r}$ value comes with an increase in permeability making solvent exchange easier. Base-catalyzed gels have a liquid permeability in the range of $10-20 \mathrm{~nm}^{2}$ and acid-catalyzed gels in the range of a few $\mathrm{nm}^{2}$. This is the paradox of gels and these are highly porous but poorly permeable aerogels.

In both cases the silica network is covered with silanol $\mathrm{Si}-\mathrm{OH}$ groups which react together with time to form water and siloxane $\mathrm{Si}-\mathrm{O}-\mathrm{Si}$ bridges. Such a reaction leads to the shrinkage of the solid part of the gel, while the liquid within the pores is expelled out of the sample. This phenomenon is called syneresis. It is thermally activated and its intensity depends on the details of the solid network texture. When silanol groups borne by the arms of solids are very close, such a phenomenon causes a significant shrinkage.

In comparison base-catalyzed gels which consist of an arrangement of large particles and which exhibit a higher mean pore size are less sensitive than acid ones. Basic gels show a weak syneresis phenomenon, and the associated shrinkage is low (Woignier et al. 2013).

In principle the capillary stresses are avoided thanks to the supercritical drying. However some thermomechanical stresses could induce cracks in the aerogel during heating and depressurization steps. The first stage of supercritical drying consists in 
Fig. 13 Example of samples submitted to a fast heating rate inducing an aerogel damage: (a) acid or neutral silica aerogel, (b) basic aerogel a

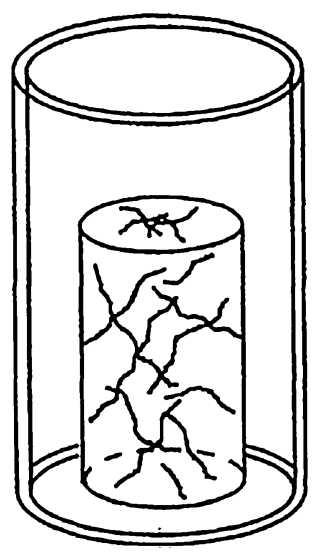

b

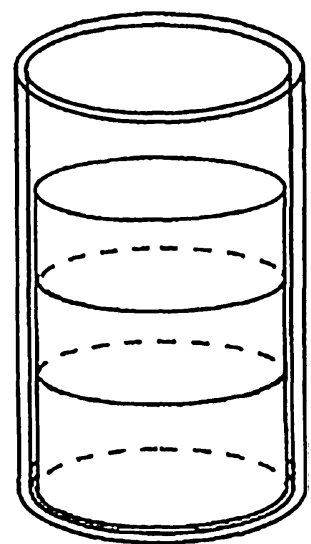

autoclave heating. Both the solid part of the gel and solvent are heated. Several features are related to this thermal treatment. As mentioned above, syneresis phenomenon takes place and the solid shrinks. On the other hand, the liquid expands. The solvent located outside the silica network moves as mentioned previously (see paragraph 3). The solvent located within the pores expands, and the liquid tends to escape from the solid network. The net effect of these two phenomena is that the solid phase is under a tensile stress. A detailed calculation of the stresses created during this first stage of supercritical drying has been reported. Stresses depend on the geometrical dimensions and the permeability of gels (Scherer 1992). The results clearly indicate that for acid or neutral gels, syneresis is the main phenomenon giving rise to high stresses which can lead to gel failure. The observed framework of cracks (Fig. 13a) is in good agreement which offered explanations and calculation. Base-catalyzed gels can be considered as macroporous. They exhibit a higher permeability and syneresis is reduced. The gel shrinkage is quite weak, and often the gel sticks to the walls of the container. Under such conditions, the liquid mainly escapes through the free upper surface of the gel. The gel network is consequently submitted to a pure uniaxial tensile stress. If the stress developed during heating becomes higher than the rupture stress, the gel breaks into several slides as indicated in Fig. 13b.

Sample dimensions and kinetic parameters play also a significant role during the depressurization step. Depressurization is carried out at about $300{ }^{\circ} \mathrm{C}$ for alcohol and at about $50{ }^{\circ} \mathrm{C}$ for $\mathrm{CO}_{2}$. It is performed during an isothermal treatment. The pressure in the autoclave is lowered at a rate controlled by the opening of a microvalve. As soon as the pressure decreases in the autoclave, the superfluid invading the pores of the gel tends to escape from the surface. Thus a fluid flow occurs from the core to the surface. If the network shows a low permeability, a pressure gradient is created and stresses occur.

As explained above, the fluid within the pores is under compressive stress and the solid network under tension. According to the quite low elastic constant of the gel, 
the network expands and cracks can happen. During the depressurization step, the supercritical fluid becomes progressively a gas as the pressure decreases. Correlatively the mean free path of molecules increases, and the fluid transport changes with pressure.

At high pressure the fluid transport can be considered as laminar. On the side of low pressure and according to the small size of pores, the fluid transport occurs by Knudsen diffusion. The mean free path of gaseous molecule is now close to the pore size. Hence the fluid is no more considered as incompressible during the depressurization. The compressibility of alcohol increases sharply below $2 \mathrm{MPa}$. G. W. Scherer has provided the theory allowing estimating the stresses which develop in gels as a function of their shape, their geometrical dimensions, and depressurization times (Scherer 1994). It is worth noticing that the calculation is more complicated than in the case of temperature increase because the permeability and the viscosity of the fluid depend both on the pressure. Moreover the calculation requires the knowledge of fluid compressibility which is connected to the gas density change with pressure. It must be noted that the gas permeability of aerogel is higher than for a liquid (Stumpf et al. 1992). This behavior is due to the Knudsen and/or Klinkenberg effect in such confined porous materials (Anez et al. 2014), depending on the gas mean free path and pore size. G.W. Scherer showed that the depressurization stresses become significant in the $0.1-2 \mathrm{MPa}$ range. The theoretical results agree with experimental data (Woignier et al. 1994).

As expected monolithicity is easier to obtain for light materials for which the permeability is relatively high compared to more dense aerogels. Moreover acidcatalyzed gel which exhibits low permeability will crack, especially those having a wide diameter and depressurized at a high rate. The experimental results are reported in Fig. 14 for gels obtained under different catalytic conditions. According to the above explained phenomena, the supercritical drying process requires a good knowledge of the textural and geometrical parameters of the samples. The heating and depressurization rates must be fitted to these parameters which vary according to the porous microstructure of the samples.

Fig. 14 Curves showing the boundary between the monolithicity region $(\mathrm{M})$ and the damaged region (D as a function of the depressurization rate (v) and the diameter (d) of cylindrical aerogels, respectively: (-) gels obtained under acidic condition, (-) gels obtained under basic condition

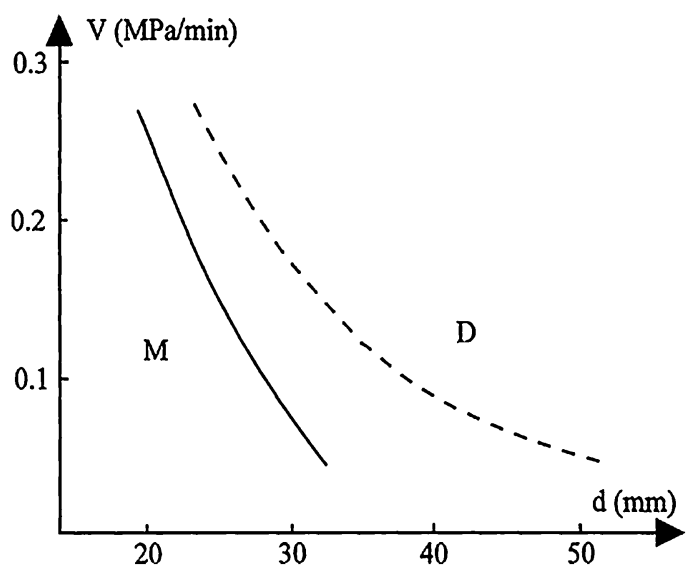




\section{Aerogels and Applications}

Because of their specific properties of very high porosity and specific surface area, aerogel materials have found many potential applications in various domains like insulation (thermal and acoustical), catalyst, aerospace, optic, energy storage, nuclear field, etc. but also in biology and life and environmental sciences. In the following we will give some examples of aerogels and their applications. These examples are not exhaustive.

The "ancient" applications of silica aerogels are related to the very low density of aerogels. Materials which are light find applications in space technology (Jones 2006; Bheekhun et al. 2013). For example, transparent aerogels have been prepared as hypervelocity particle capture in space (cosmic particles) (Tsou 1995). The "stardust project" mission returned to earth in January 2006 providing sample dust from a comet. Captors for debris in the vicinity of the International Space Station (ISS) (MEDET program, Material Exposure and Degradation Experiment) (Labat et al. 2013) were low density and transparent silica aerogels (Woignier et al. 2013). The low mechanical properties and the transparency allow capture and easy detection of cosmic particles and debris.

Aerogels have been used for nuclear reaction performed by inertial confinement fusion and for Cerenkov radiators (Kim and Jang 1991; Hrubesh 1998; Yokogawa 2011). Transparent aerogels with low refractive index are interesting as Cerenkov counter in high-energy physics. In a low refractive index material, the elementary particles travel with a velocity lower than the light velocity in air (celerity), and they emit photons called Cerenkov effect allowing calculating the particle velocity. These experiments need low refractive index close to 1 which can be achieved in light aerogels. These aerogels have porosities higher than $95 \%$. Both silica and carbon aerogels have been investigated.

Because of the low density, silica aerogels were also good candidates for thermal and acoustic insulation. The thermal conductivity of silica aerogels is close to 0.015 $10^{-2} \mathrm{Wm}^{-1} \mathrm{~K}^{-1}$ at ambient pressure and temperature lower than in air $(0.025$ $\mathrm{Wm}^{-1} \mathrm{~K}^{-1}$ ) (Yoldas et al. 2000; Pierre and Rigacci 2011). The acoustic properties of silica aerogels are related to the thermal conductivity. The sound propagation depends on the aerogel density and tortuosity (fractal structure). The acoustic wave is attenuated in velocity and in amplitude leading to a localization phenomenon (Forest et al. 1998). The sound velocity is typically $100 \mathrm{~m} / \mathrm{s}$ (Gross and Fricke 1992; Forest et al. 2001), three times lower than in air. Thus silica aerogels are among the best thermal and acoustical insulating materials (Hrubesh 1998). These properties are the consequence of the large pore volume but clearly to the tortuous microstructure of the porosity.

To obtain light silica aerogels, it is first necessary to optimize the gel formation. First, the hydrolysis is advantageously improved using a previous treatment step which consists of performing a hydrolysis with a sub-stoichiometric amount of an acidic aqueous solution. The solution is distilled to remove alcohol, and this concentrated highly hydrolyzed solution is then diluted in acetone. In a second step the gelation (condensation reaction) is performed using basic aqueous solution 
diluted in the nonalcoholic solvent. This two-step process permits to prepare transparent aerogels having densities within the range $8-80 \mathrm{~kg} / \mathrm{m}^{3}$ (Boonstra and Mulder 1988).

A more simple two-step process performed with alcohol as solvent permits to gel solutions containing a small amount of alkoxides (Tillotson and Hrubesh 1992). In any case the density of obtained aerogel mainly depends on the sample shrinkage which occurs inside the autoclave.

The shrinkage could be due to the silica solubility and to the cluster restructuring which is related to the strength of the links connecting clusters. Silica dissolution leads to a weakening of these links. The silica solubility can be lowered by using an appropriate solvent composition (Kocon et al. 1998) or by adding solid-specific oxide-like zeolite in the alcoholic solvent (Yoda et al. 1998).

To obtain low-density organic aerogels, it seems that a double step is also required. Gel formation from phloroglucinol and formaldehyde is carried out using a base as catalyst. This first step provides methylol groups on phenolic rings. The second step consists of catalyzing the polycondensation reaction using an acidic aqueous solution. Densities as low as $13 \mathrm{~kg} / \mathrm{m}^{3}$ are produced (Barral 1998).

For other applications (host matrix for chemical species, precursor for glass, ceramics, or composites), the silica aerogels should have high mechanical properties and consequently high density. Several methods have been devoted to monolithic aerogels having the highest densities. These aerogels are comparatively stronger than "insulating aerogels." This goal, for example, can be achieved by adding silica particles (silica soot) in the starting solution (Toki et al. 1988) and then performing a supercritical drying treatment (Marlière et al. 2001). However, the inclusion of particles affects the aggregation process and modifies the porous structure. It is thus possible to adjust the density, the mechanical properties, the pore size distribution, and the permeability of the composite aerogels by adding silica powder.

A different way to prepare dense aerogel consists of minimizing the amount of alcohol. At the onset of reaction, the solution is not homogeneous. A vigorous mechanical or ultrasonic stirring is required to form droplets with a significant increase in the reacting surface. As soon as the hydrolysis reaction starts, alcohol molecules are formed, and with time the different liquids become miscible. These gels are called "sonogels," and densities higher than $0.98 \mathrm{~g} / \mathrm{cm}^{3}$ are obtained (Esquivias and Zarzycki 1988). Numerous systems have been synthesized by sonocatalysis $\mathrm{SiO}_{2}-\mathrm{P}_{2} \mathrm{O}_{5}, \mathrm{SiO}_{2}-\mathrm{TiO}_{2}$ and $\mathrm{Si}_{2}-\mathrm{Al}_{2} \mathrm{O}_{3}-\mathrm{MgO}$ (Esquivias et al. 2011).

After aerogel synthesis, an additional step can increase the bulk density: by sintering at a high temperature $\left(1000{ }^{\circ} \mathrm{C}\right)$ (Woignier et al. 1990) or by isostatic pressure (Perrin 2004). The sintering process eliminates completely the porosity depending on the treatment duration. The sintering allows synthesizing silica glass with the same properties than fused silica. The process has been extrapolated to borosilicate and phosphosilicate glasses. The densification by compression collapses the large pores and allows the control of porosity closer than $40 \%$. For higher density (lower porosity), the aerogels are destroyed by high pressure. This process could have some applications in the case of trapping chemical or biological species which cannot resist to the high sintering temperature. 
Silica aerogels dried using alcohol show hydrophobic properties as they are obtained. As explained before an esterification reaction occurs inside the autoclave, and $\mathrm{Si}-\mathrm{OH}$ groups are transformed into $\mathrm{Si}-\mathrm{OR}\left(\mathrm{R}=\mathrm{CH}_{3}, \mathrm{C}_{2} \mathrm{H}_{5}\right.$, etc.). However with time, these chemical groups react with air moisture, and the material becomes again hydrophilic. Water then condenses in the pores and creates again capillary forces. Silica aerogels dried using $\mathrm{CO}_{2}$ are hydrophilic, and air moisture adsorption cannot be avoided.

To circumvent these problems, some authors suggest to prepare gels using chemical precursors such as $\mathrm{R}-\mathrm{Si}-(\mathrm{OR})_{3}$ where $\mathrm{R}$ is a methyl of ethyl group. These particular chemical $\mathrm{Si}-\mathrm{R}$ groups are not subject to hydrolysis and polycondensation reactions. Another way is to perform a reaction of trimethylsilylation. Such a reaction is generally done with trimethylchlorosilane or using hexamethyldisilazane (Yokogawa and Yokoyama 1995). This process may be used to passivate the surface of low-cost gels issued from water glass solutions (Schwertfeger et al. 1998). These special xerogels belong to a family of "aerogellike" materials. However the pore volume of the aerogel like is comparatively lower than that of conventional aerogels (Land et al. 2003).

Besides the well-described silica aerogels, other oxide aerogels $\left(\mathrm{ZrO}_{2}, \mathrm{TiO}_{2}\right.$, hafnium niobium, tantalum, etc.) have been synthesized and studied in the literature. In the following, we will give some non-exhaustive kind of aerogels and their potential applications.

Zirconia aerogels possess properties for catalyst applications; the surface has both oxidizing and reducing properties. Doped zirconia aerogels are interesting for reactions with hydrogen and for isomerization of butenes (Pajonk and El Tanany 1992). Doping with rhodium and yttrium leads to interesting catalysts for methane oxidation (Sermon et al. 1997).

Titania aerogels have potential application as photocatalyst, gas sensors, and solar application cells (Wyley et al. 1995; Pietron and Rolisson 2004; Kucheyev et al. 2004; Chen et al. 2006). Transition metallike $\mathrm{Fe}_{2} \mathrm{O}_{3}$, chromia, and ruthenium oxide aerogels are studied for a variety of application like magnetic nanomaterials, energy, and catalysis (Gash et al. 2001; Suh et al. 2003; Bali et al. 2009).

Semiconductor aerogels were made with chalcogenides [Mohanan et al. 2005; Bag et al. 2007). The properties of metal chalcogenides exhibit band gap semiconductivity. The porous aerogel has a large porosity and specific surface area and presents the same quantum confinement effect than the building nanoparticles. Coupling the chalcogenide properties with the large porosity is interesting for applications like solar cells and sensor but also environmental application like sorption of aromatic molecules (Brock and Yu 2011).

Organic aerogels were proposed first from resorcinol-formaldehyde reacted in aqueous solution (Pekala and Kong 1989). Water is exchanged with alcohol or acetone. Supercritical drying is performed with $\mathrm{CO}_{2}$, and transparent organic aerogels have been prepared from a mixture of melamine-formaldehyde (Pekala et al. 1992). Resorcinol-formaldehyde aerogel is an important class of organic aerogels; they were studied for their uses as thermal insulator but also as precursor for carbon aerogel. Carbon aerogels were considered for energy storage, 
supercapacitor applications, and filtration. Carbon aerogels can be synthesized by pyrolysis of resorcinol-formaldehyde under inert atmosphere. Gels of the same family are also prepared from phloroglucinol (Barral 1998) and polyurethane (Biesmans et al. 1998a). Polyurethane aerogels were developed for insulation application (Lee and Gould 2009; Yim et al. 2002) but also have bas precursor for carbon aerogels (Biesmans et al. 1998b).

A way to expand the potential of aerogels is the synthesis of composites materials. Composite aerogels are formed by the combination of several phases, and sol-gel chemistry allows the building of the composites at the nanoscale. It exists in a wide range of composite aerogels: by a cosynthesis with different alkoxides or with salts in the solution and by the combination of organic and inorganic phases (these composites are also called "hybrid"). The most ancient way to synthesize nanocomposite is to use the large pore volume of aerogels (or alcogels) to introduce the secondary phase. The combination of the high porosity and specific surface area is an advantage to entrap chemical species (Woignier et al. 2005).

This method has been used in the domain of the nuclear waste containment. The actinide surrogates $(\mathrm{Nd}, \mathrm{Ce})$ were introduced in a silica matrix to be trapped with a further sintering. The nanocomposites actinides-silica glass present good chemical durability and thermomechanical properties required for the nuclear waste containment technology (Aravind et al. 2008; Reynes et al. 2001). $\mathrm{ZnO}$ were introduced in the porosity of silica aerogels by immersion of $\mathrm{ZnSO}_{4}$; the nanocomposites present improved photoluminescent properties compared to bulk $\mathrm{ZnO}$ (Mo et al. 1998). In the same way, tin-silica nanocomposites have been synthesized, and the composites present interesting photocatalytic properties in methylene blue degradation (Wei et al. 2008). Entrapped chemical species can be luminescent molecule (Leventis et al. 1999; Wei et al. 2007) deuterium and tritium for fusion experiments (Kim and Jang 1991) or liquid crystals (Fehr et al. 2003). Bacteria (Escherichia coli) associated with green fluorescent protein have been entrapped in aerogels forming a biosensor for viruses (Power et al. 2001).

Bio- or natural aerogels have been studied these last 10 years. An interest has grown in the field of biocompatible aerogels for biomedical and pharmaceutical applications. For drug delivery, biocompatibility and biodegradability are generally required (Smirnova et al. 2003; Smirnova et al. 2004). Some resorcinol and formaldehyde loaded with methadone and 5-fluorouracil are reported in the recent literature (Lee and Gould 2006). Polysaccharide aerogels were also described with a high potential for drug release (Valentin et al. 2005). The chitosan-silica aerogel composite (Chang et al. 2008; Valentin et al. 2007) exhibits a high drug loading with a better control of the drug release than silica (Yao et al. 2011). Enzymes and proteins can be stabilized in silica alcogels and aerogels (El Rassy 2003; Basso et al. 2000). Because of the high and adjustable porosities, aerogels are candidates as tissue engineering (Toledo-Fernandez et al. 2008).

In the domain of environmental applications, sono-aerogels containing wollastonite exhibit interesting properties for the greenhouse gas (GHG) sequestration. The $\mathrm{CO}_{2}$ reacts with wollastonite and is transformed into calcite. The large porosity and the high specific surface area of aerogel favor the $\mathrm{CO}_{2}$ transformation (Santos et al. 
2008). Allophane is a natural clay gels able to sequestrate GHG (Chevallier et al. 2010). Allophane is also able to contain pesticides reducing the release of pesticide in water and crops (Cabidoche et al. 2009). The synthesis of allophane aerogels by $\mathrm{CO}_{2}$ supercritical drying has demonstrated the influence of the fractal structure of the allophane clay, on the environmental properties of GHG sequestration and pesticide trapping (Woignier et al. 2015).

\section{Conclusion}

The supercritical drying process which was first proposed by S.S. Kistler is now well controlled. It requires a good knowledge of the role played by the different process parameters. These parameters must be carefully selected as a function of the structural, textural, and dimensional properties of samples.

Supercritical drying is an almost universal way to dry gel sample avoiding the shrinkage and the loss of pore volume. It may be applied to a lot of mineral gels (Kistler 1932 and Gash et al. 2001) and organic ones. Alcohol and acetone are the preferred solvents when the solid network resists temperature within the range $100-300{ }^{\circ} \mathrm{C}$. For the lowest temperatures, $\mathrm{CO}_{2}$ is the most suitable solvent. It usually requires a previous solvent exchange. Aerogels are nanoporous materials consisting of an open cell network having exceptional physical properties in various area of technology. The aerogels have lower density, thermal conductivity, sound velocity, and refractive index than any other solids. Because of these properties, some applications are in the fields of the thermal and acoustical insulation but also are electronics, optics, chemistry, and pharmacy. Some exotic application like cosmic particles and debris captors, nuclear waste process, and GHG sequestration shows that the future domains of the aerogels technology are probably not yet well defined.

We must also underline that the chemical nature of the aerogel can be changed by reacting the porous solid with an invading gas. Silica aerogels have been nitrided by ammonia. They are converted into dense homogeneous oxynitride glasses having about $10 \mathrm{wt} . \%$ of nitrogen. This thermal resistant material requires temperatures close to $1600{ }^{\circ} \mathrm{C}$ to be fully sintered (Szaniawska et al. 2001).

Obtained aerogels are usually monolithic. They are used as obtained, but owing to their huge porous volume, they can be considered as a host matrix into which guest molecules can be trapped. Consequently it is possible to modify the properties of the aerogel according to the nature of the guest molecules. According to the possibility to tailor their textural properties and the possibility to sinter them up to a chosen density, they are now considered as precursors to prepare new composite materials.

The sol-gel and aerogel methods have some drawbacks (generally high cost of raw materials, long processing time, quite low mechanical properties). But it is one of the best appropriate processes to synthesize highly porous solids. Moreover the aerogel process combines several advantages. The association of the flexibility of the glass and ceramic technology (which allows a large domain of composition) and the flexibility of a sol-gel process (with a great liberty to control the pore structure) allows tailoring the material physical and chemical properties to attain the specific objective. 


\section{References}

Aegerter AM, Leventis N, Koebel MM. Aerogels handbook. New York: Springer; 2011.

Anez L, Calas-Etienne S, Primera J, Woignier T. Gas and liquid permeability in nano composites gels: comparison of Knudsen and Klinkenberg correction factors. Microporous Mesoporous Mater. 2014;200:79-85.

Aravind PR, Sithara L, Mukundan P, Krishna PP, Warrier KGK. Silica alcogels for possible nuclear wastes confinement- a simulated study. J Mater Sci Lett. 2007;61:2398-401.

Aravind PR, Shajesh P, Mukundan P, Krishna PP, Warrier KGK. Non- supercritically dried silicasilica composites aerogel and its possible application for confining nuclear wastes. J Sol-Gel Sci Technol. 2008;46:146-51.

Bag S, Trikalitis PN, Chupas PJ, et al. Porous semiconducting gels and aerogels from xhalcogenide clusters. Science. 2007;317:490-3.

Baker LCW, Anderson TF. Some phase relationships in the three-component liquid system. J Am Chem Soc. 1957;79(2):2071-4.

Bali S, Huggins FE, Huffman GP, Ernst RD, Pugmire RJ, Eyring EM. Iron aerogels and xerogels catalysts for fischer-Tropsch synthesis of diesel fuel. Energy Fuel. 2009;23:14-8.

Barral K. Low density organic aerogels by double-catalysed synthesis. J Non-Cryst Solids. 1998;225:46-50.

Basso B, De Martin L, Ebert C, Gardoss C, Tomat T, Casarci M, Li RO. A novel support for enzyme adsorption: properties and applications of aerogels in low water media. Tetrahedron Lett. 2000;41:8627-30.

Bheekhun N., Abu Talib A.R. Hassan M.R.. Aerogels in aerospace: an overview. Adv Mater Sci Eng. 2013; 2013: 406065, 18 pages. 10.1155/2013/406065.

Biesmans G, Randall D, Français E, Perrut M. Polyurethane-based organic aerogels'thermal performance. J Non-Cryst Solids. 1998a;225:36-40.

Biesmans G, Mertens A, Duffours L, Woignier T, Phalippou J. Polyurethane based organic aerogels and their transformation into carbon aerogels. J Non-Cryst Solids. 1998b;225:64-8.

Boonstra AH, Mulder CAM. effect of hydrolytic polycondensation of tetraethoxysilane on specific surface area of $\mathrm{SiO}_{2}$ gels. J Non-Cryst Solids. 1988;105:201-6.

Brinker, Scherer, Sol-gel science New York :Academic (1990).

Brock SL, Yu H. Chalcogenide aerogels, Chap. 17. In: Aegerter MA, Leventis N, Koebel MM, editors. Aerogels handbook. New York: Springer Science; 2011. p. 367-84.

Cabidoche YM, Achard R, Cattan P, Clermont-Dauphin C, Massat F, Sansoulet J. Long-term pollution by chlordecone of tropical volcanic soils in the French West Indies: a simple leaching model accounts for current residue. J Environ Pollut. 2009;157:1697-705.

Chang X, Chen D, Jiao X. Chitosan-based aerogels with high adsorption performance. J Phys Chem B. 2008;112:7721-5.

Chen L, Zhu J, Liu YM, Cao Y, Li HX, He H, Dai W, Fan K. Photocatalytic activity of epoxide sol-gel derived titania transformed into nanocrystalline aerogel powders by supercritical drying. J Mol Catal A Chem. 2006;255:260-8.

Chevallier T, Woignier T, Toucet J, Blanchart E. Carbon sequestration in the fractal porosity of Andosols. Geoderma. 2010;159:182-8.

Degn EE, Engell J. Freeze drying of silica gels prepared from silicium methoxide. Rev Phys Appl. 1989;C4-24:23-8.

Einarsrud MA. Light gels by conventional drying. J Non-Cryst Solids. 1998;225:1-7.

El Rassy H, Maury S, Buisson P, Pierre AC. Hydrophobic silica aerogel-lipase biocatalysts - Possible interactions between the enzyme and the gel. J Non-Cryst Solids. 2004;350:23-30.

Esquivias L, Zarzycki J. Sonogels : an alternative method in sol-gel processing. In: Mackenzie JD, Ulrich DR, editors. Ultrastructure processing of advanced ceramics. New York: Wiley; 1988. p. $255-70$.

Esquivias L, Pinero M, Morales-Florez V, Dela Rosa Fox N. Aerogels synthesis by sonocatalysis : sonogels, Chap. 20. In: Aegerter MA, Leventis N, Koebel MM, editors. Aerogels handbook. Springer Science; 2011. p. 419-48. 
Fehr C, Diuedonné P, Primera J, Woignier T, Sauvajol JL, Anglaret E. Solid state polymorphism of liquid crystals in confined geometries. Eur Phys J E. 2003;12:13-66.

Forest L, Gibiat V, Woignier T. Biot's Theory of acoustic propagation in porous media applied to aerogels and alcogels. J Non-Cryst Solids. 1998;225:477-48.

Forest L, Gibiat V, Hooley A. Impedance matching and acoustic absorption in granular layers of silica aerogels. J Non-Cryst Solids. 2001;285:230-5.

Francis AW. Ternary systems of liquid carbon dioxide. J Phys Chem. 1954;58:1099-114.

Gash AE, Tillotson TM, Satcher Jr JH, Hrubesh LW, Simpson RL. New sol-gel synthetic route to transition and main-group metal oxide aerogels using inorganic salt precursors. J Non-Cryst Solids. 2001;285:22-8.

Gross J, Fricke J. Ultrasonic velocity measurement in silica, carbon and inorganic aerogels. J Non-Cryst Solids. 1992;145:217-22.

Gross J, Coronado PR, Hrubesh LW. Elastic properties of silica aerogels from a new rapid supercritical extraction process. J Non-Cryst Solids. 1998;225:282-6.

Hench LL. Use of drying control chemical addition (DCCAs) in controlling sol-gel processing. In: Hench LL, Ulrich DR, editors. Science of ceramic chemical processing. New York: Wiley; 1986. p. 52-64.

Hrubesh LW. Aerogel applications. J Non-Cryst Solids. 1998;225:335-42.

Jones SM. Aerogels: space explorations applications. J. Sol-Gel Sci Tech. 2006;40:351-7.

Kim KK, Jang KY. Hollow silica spheres of controlled size and porosity by sol-gel processing. J Am Ceram Soc. 1991;74:1987-92.

Kistler SS. Coherent expanded aerogels. J Phys Chem. 1932;34:52-64.

Kocon L, Despetis F, Phalippou J. Ultralow density silica aerogels by alcohol supercritical drying. J Non-Cryst Solids. 1998;225:96-100.

Kucheyev SO, van Buuren T, Baumann TF, Satcher JH, Willey TM, Meulenberg RW, Felter TE, Poco JF, Gammon SA, Terminello LJ. Electronic structure of titania aerogels from soft x-ray absorption spectroscopy. Phys Rev B. 2004;69(24):245102. https://doi.org/ 10.1103/PhysRevB.69.245102.

Labat L., Durin C., Remaury S., Mandeville J.C., Rejsek-Riba V., Duzellier S., Duffours L., Colombel P., Woignier T.2013), CNES experiments on MEDET Astrophysics and space science proceedings 32 Masahito Tagawa, Jacob Kleinman,Yugo Kimoto Springer Heidelberg/New York/Toronto/London, 978-3 642-30228-2, 217-234

Land VD, Harris TM, Teeters DC. Processing of low density silica gels by critical point drying or ambient pressure drying. J Non-Cryst Solids. 2001;283:11-7.

Land VD, Harris TM, Henshaw JM. Effect of gel modulus on the porosity of low-density silica. J Non-Cryst Solids. 2003;316:238-45.

Lee J. K., Gould G.L. Aerogel powder therapeutic agents. US Patent 6994842. 2006.

Lee JK, Gould GL. Polyurea based aerogel for a high performance thermal insulation material. J. Sol-Gel Sci. and Tech. 2009;49:209-20.

Leventis N, Elder IA, Rolison DR, Anderson ML, Merzbacher CI. Durable modification of silica aerogel monoliths with fluorescent 2,7-diazapyrenium moieties. Sensing oxygen near the speed of open-air diffusion. Chem Mater. 1999;11:2837-45.

Leventis N, Sotitiou-Leventis C, Zhang G, Rawashdeh A-MM. Nanoengineering strong silica aerogels. Nano Lett. 2000;2(9):957-60.

Loy DA, Russick EM, Yamanaka SA, Baugher BM, Shea KJ. Direct formation of aerogels by sol-gel polymerization of alkoxysilanes in supercritical carbon dioxide. Chem Mater. 1997;9:2264-8.

Marlière C, Woignier T, Dieudonné P, Primera J, Lamy M, Phalippou J. Two fractal structure in aerogel. J Non-Cryst Solids. 2001;285:175-81.

Martin J, Hostika B, Lattimer C, Norris PM. Mechanical and acoustical properties as a function of PEG concentration in macroporous silica gels. J Non-Cryst Solids. 2001;285:222-9.

Mezza P, Phalippou J, Sempere R. Sol-gel derived porous silica films. J Non-Cryst Solids. 1999;243:75. 
Mizuno T, Nagata H, Manabe S. Attempts to avoid cracks during drying. J Non-Cryst Solids. 1988;100:236-40.

Mo C.M., Li Y.H., Liu Y.S.,Zhang Y., Zhang L.D, Enhancement effect of photoluminescence in assemblies of nano-ZnO particles/silica aerogels, J Appl Phys 1998; 83: 4389-4391

Mohanan JL, Arachchige IU, Brock SL. Porous semiconductor chalcogenide aerogels. Science. 2005;307:397-400.

Mulder CAM, Van Lierop JG. Preparation, densification and characterization of autoclave dried $\mathrm{SiO}_{2}$ gels. In: Fricke J, editor. Aerogels, springer proceedings in physics. 6 Heidelberg: Springer; 1986. p. 68-75.

Pajonk GM. Drying methods preserving the textural properties of gels. Rev Phys Appl. 1989; C4-24:13-22.

Pajonk GM, El Tanany A. Isomerization and hydrogenation of butane-1 on a zirconia aerogel catalyst. React Kinet Catal Lett. 1992;47:167-75.

Panagiotopoulos AZ, Reid RC. High pressure phase in ternary fluid mixtures with a supercritical component. Am Chem Soc Div Fuel Chemi. 1985;30(3):46-56.

Pauthe M, Quinson JF, Hdach H, Woignier T, Phalippou J, Scherer GW. Autoclave treatment effect on silica alcogel texture. J Non-Cryst Solids. 1991;130:1-7.

Pekala RW, Kong FM. A synthetic route to organic aerogels. Mechanism, structure and properties. Rev Phys Appl. 1989;C4(4):33-40.

Pekala RW, Alviso CT, Kong FM, Hulsey SS. Aerogels derived from multifunctional organic monomers. J Non-Cryst Solids. 1992;145:90-8.

Perin L, Faivre AL, Calas-Etienne S, Woignier T. Nanostructural damage associated with isostatic compression of silica aerogels. J Non-Cryst Solids. 2004;333:68-73.

Phalippou J, Woignier T, Prassas M. Glasses from aerogels. Part I : the synthesis of monolithic aerogels. J Mater Sci. 1990;25:3111-7.

Pierre AC, Rigacci A. SiO2 aerogels, Chap 2. In: Aegerter MA, Leventis N, Koebel MM, editors. Aerogels handbook. New York: Springer Science; 2011. p. 21-46.

Pietron JJ, Rolisson DR. Improving the efficiency of titania aerogel-based photovoltaic electrodes by electrochemically grafting isopropyl moieties on the titania surface. J Non-Cryst Solids. 2004;350:107-12.

Power M, Hosticka B, Black E, Daitch C, Norris P. Aerogels as biosensors: viral particle detection by bacteria immobilized on large pore aerogel. J Non-Cryst Solids. 2001;285:303-8.

Prakash SS, Brinker CJ, Hurd AJ. Silica aerogels films at ambient temperature. J Non-Cryst Solids. 1995;190:264-75.

Prassas M, Phalippou J, Zarzycki J. Synthesis of monolithic silica gels by hypercritical solvent evacuation. J Mater Sci. 1984;19:1656-65.

Reynes J, Woignier T, Phalippou J. Permeability measurements in composites aerogels: application to nuclear waste storage. J Non-Cryst Solids. 2001;85:323-7.

Rogacki G, Wawrzyniak P. Diffusion of ethanol-liquid $\mathrm{CO}_{2}$ in silica aerogel. J Non-Cryst Solids. 1995;186:73-7.

Santos A, Ajbary M, Kherbeche A, Pinero M, De la Rosa-Fox N, Esquivias L. Fast $\mathrm{CO}_{2}$ sequestration by aerogel composites. J Sol-Gel Sci Technol. 2008;45:291-7.

Scherer GW. Stress development during supercritical drying. J Non-Cryst Solids. 1992;145:33-40.

Scherer GW. Freezing gels. J Non-Cryst Solids. 1993;155:1-25.

Scherer GW. Stress in aerogel during depressurization of autoclave : I. Theory. J Sol-Gel Sci Tech. 1994;3:127-39.

Schwertfeger F, Frank D, Schmidt M. Hydrophobic waterglass based aerogels without solvent exchange or supercritical drying. J Non-Cryst Solids. 1998;225:24-9.

Sermon PA, Self VA, Sun Y. Doped zirconia aerogels: catalyst and controlled structures and properties. J. Sol-Gel Sci. and Tech. 1997;8:851-6.

Shoup RD. Complex fused silica shapes by a silicate gelation process. In: Mackenzie JD, Ulrich DR, editors. Ultrastructure processing of advanced ceramics. New York: Wiley; 1988. p. $347-54$. 
Smirnova I, Mamic J, Arlt W. Adsorption of drugs on silica aerogels. Langmuir. 2003;19:8521-5.

Smirnova I, Suttiruengwong S, Seiler M, Arlt W. Dissolution rate enhancement by adsorption of poorly soluble drugs on hydrophilic silica aerogels. Pharm Dev Technol. 2004;9:443-52.

Stumpf C, Gässler KV, Reichenauer G, Fricke J. Dynamic gas flow measurements on aerogels. J Non-Cryst Solids. 1992;145:180-4.

Suh DJ, Park T, Kim W, Hong I. Synthesis of high surface area ruthenium oxide aerogels by non alkoxide sol -gel route. J Power Sources. 2003;117:186-91.

Szaniawska K, Murawski L, Pastuszac R, Walewski M, Fantozzi G. Nitridation and densification of $\mathrm{SiO}_{2}$ aerogels. J Non-Cryst Solids. 2001;286:58-63.

Tillotson TM, Hrubesh LW. Transparent ultralow density silica aerogels proposed by a two-step process. J Non-Cryst Solids. 1992;145:44-50.

Toki M, Miyashita S, Takeuchi T, Kande S, Kochi A. A large-size silica glass produced by a new sol-gel process. J Non-Cryst Solids. 1988;100:479-82.

Toledo-Fernandez JA, Mendoza-Serna R, Morales V, De la Rosa-Fox N, Pinero M, Santos A, Esquivias L. Bioactivity of wollastonite/aerogels composites obtained from a TEOS-MTES matrix. J Mater Sci Mater Med. 2008;19:2207-13.

Tsou P. Silica aerogel captures cosmic dust intact. J Non-Cryst Solids. 1995;186:415-27.

Valentin R, Horga R, Bonelli B, Garrone E, Di Renzo F, Quignard F. Acidity of alginate aerogels studied by FTIR spectroscopy of probe molecules. Macromol Symp. 2005;230:71-7.

Valentin R, Bonelli B, Garrone E, Di Renzo F, Quignard F. Accessibility of the functional groups of chitosan aerogel probed by FT-IR-monitored deuteration. Biomacromolecules. 2007;8:3646-50.

Van Bommel MJ, de Haan AB. Drying of silica gels with supercritical carbon liquid. J Mater Sci. 1994;29:943-8.

Venkateswara Rao A, Kulkarni MM. Effect of glycerol additive on physical properties of hydrophobic silica aerogels. Mater Chem Phys. 2003;77:819-25.

Vuillard G, Sanchez M. Vitrification et cristallisation dans le système binaire eau - méthanol. Bull Soc Chim Fr. 1961;10:1877-80.

Wang SY, Wu NL. Tin acid gel shrinkage during $\mathrm{CO}_{2}$ supercritical drying. J Non-Cryst Solids. 1998;224:259-66.

Wawrzyniak P, Rogacki G, Pruba J, Bartczak Z. Effective diffusion coefficient in the low temperature process of silica aerogel production. J Non-Cryst Solids. 2001;285:50-6.

Wei TY, Lu SY, Chang YC. Rich photoluminescence emission of $\mathrm{SnO}_{2}-\mathrm{SiO}_{2}$ composite aerogels prepared with a co-fed precursor sol-gel process. J Chin Inst Chem Eng. 2007;38:477-81.

Wei TY, Kuo CY, Hsu YJ, Lu SY, Chang YC. Tin oxide nanocrystals embedded in silica aerogel: photoluminescence and photocatalysis. Microporous Mesoporous Mater. 2008;112:580-8.

Woignier T. Contribution à l'obtention de verres par la voie sol-gel [PhD dissertation]. Montpellier; 1984.

Woignier T, Phalippou J, Prassas M. Glasses from aerogels part 2: the aerogel glass transformation. J Mater Sci. 1990;25:3118-26.

Woignier T, Scherer GW, Alaoui A. Stress in aerogel during depressurization of autoclave : II silica gels. J Sol-Gel Sci Tech. 1994;3:141-50.

Woignier T, Primera J, Lamy M, Fehr C, Anglaret E. The use of gels as host matrices for chemical species. Different ways to control the permeability and the mechanical properties. J Non-Cryst Solids. 2005;350:298-306.

Woignier T, Primera J, Duffours L, Dieudonné P. Preservation of the allophanic soils structure by supercritical drying. Microporous Mesoporous Mater. 2007;109(1-3):370-5.

Woignier T, Duffours L, Colombel P, Durin C. Aerogels materials as space debris collectors. Adv Mater Sci Eng. 2013;2013:484153 .6 pages

Woignier T., Duffours L., Colombel P., Dieudonné P.. Nanoporous clay with carbon sink and pesticide trapping properties. Eur Phys J. 2015; 224: 1945-1962, Special Topics.

Wyley RJ, Wang CT, Peri JB. Vanadium-titanium oxide aerogels catalysts. J Non-Cryst Solids. 1995;186:408-14. 
Yao CJ, Liu X, Risen WM. biopolymer containing aerogels : chitosan silica hybrid aerogels, Chap. 18. In: Aegerter MA, Leventis N, Koebel MM, editors. Aerogels handbook. New York: Springer Science; 2011. p. 385-401.

Yim TJ, Kim SY, Yoo KP. Fabrication and thermophysical characterization of nano-porous silicapolyurethane hybrid aerogel by sol-gel processing and supercritical solvent drying technique. Korean J Chem Eng. 2002;19:159-66.

Yoda S, Ohshima S, Ikazaki F. Supercritical drying with zeolite for the preparation of silica aerogels. J Non-Cryst Solids. 1998;231:41-8.

Yokogawa H. Transparent silica aerogels blocks for high energy physics research, chap. 28. In: Aegerter MA, Leventis N, Koebel MM, editors. Aerogels handbook. New York: Springer Science; 2011. p. 651-64.

Yokogawa H, Yokoyama M. Hydrophobic silica aerogels. J Non-Cryst Solids. 1995;186:23-9.

Yoldas BE, Annen MJ, Bostaph J. Chemical engineering of aerogel morphology formed under nonsupercritical conditions for thermal insulation. Chem Mater. 2000;12:2475-84. 